\title{
FINANCIAL INSTRUMENTS AND THE RULES OF EU STATE AID
}

\author{
NATELA VASHAKIDZE
}

https://doi.org/10.35945/gb.2017.03.014

Asociated Professor of Akaki Tsereteli state University, Kutaisi, Gerogia

\section{DEZDEMONA MAGLAKELIDZE}

Asociated Professor of Akaki Tsereteli state University, Kutaisi, Gerogia

\section{KEYWORDS: FINANCIAL INSTRUMENTS, STATE AID RULES}

The European Union is currently facing serious challenges such as the economic and financial recovery and themanagement of the refugee crisis. Therefore, the EU's decision-makers are seeking ways to maximise the effectivenessand efficiency of the available EU budget, which accounts for less than $1 \%$ of the EU's gross domesticproduct (GDP).

Financial instruments are a delivery tool to provide financial support from the EU budget. Financial support provided to final recipients through financial instruments may take the form of loans, guarantees and equity investments.

If properly implemented, financial instruments provide two specific benefits compared to grants: - the possibility of leveraging the public funds (i.e. mobilising additional private and public funds to complement the initial public funding); and - the revolving nature of their capital endowment (i.e. the use of the same funds in several cycles). The fact that loans have to be paid back and guarantees have to be released or, in the case of equity investments, returned it should in principle also have an impact on the behaviour of final recipients, leading to the better use of public funds and reducing the likelihood that the final recipients will become dependent on public support.

During the 2007-2013 programme period financial instruments set up under the European Regional Development Fund (ERDF) and the European Social Fund (ESF) were used by 25 out of 28 EU Member States: in total, 972 ERDF and 53 ESF financial instruments were set up across the EU. By the end of 2014 , around 16 billion euro had been paid as contributions from the ERDF and ESF operational programmes (OPs) to these instruments. This represents a significant increase compared to around 1.3 billion in the $2000-2006$ programme period and 0.6 billion euro in the 1994- 1999 programme period allocated to such instruments. During the same period, 2007-2013, the overall contribution from the EU budget to the 21 financial instruments managed directly or indirectly by the Commission was about 5.5 billion euro. These centrally managed financial instruments operate across all EU Member States.

Compared to grants (which are the traditional way of providing funding from the EU budget), financial instruments, if properly implemented, can provide two specific benefits: the possibility of leveraging the public funds (i.e. mobilising additional private and public funds to complement the initial public funding); and the revolving nature of their capital endowment (i.e. the use of the same funds in several cycles) allows each euro of funding through financial instruments in principle to be used more than once.[3,12]

A common definition for financial instruments was first provided in the revision of the financial regulation in 2012; this definition has since been applied in the sectorial regulations for the 2014-2020 programme period (see Annex II).

The EU budget can be implemented through shared management (i.e. in cooperation with Member States such as in cohesion policy), through direct management (i.e. by its departments or through executive agencies) or through indirect management (i.e. by entrusting budget implementation tasks to third countries or to different entities)9. The latter two are collectively referred to as centralised management.

Financial instruments are used in different parts of the EU budget: Shared management financial instruments in the area of cohesion are set up mainly under the European Regional Development Fund (ERDF), and to a lesser extent under the European Social Fund (ESF). Since the 2014-2020 programme period, financial instruments can also be used for the Cohesion Fund (CF). Each instrument has to be implemented within the framework of an operational programme (OP), which is decided by the managing authorities responsible for that programme, together with its size and design10. Financial instruments are also used under the European Agricultural Fund for Rural Development (EAFRD) and the European Fisheries Fund (EFF). Centrally managed financial instruments are financed from various budgetary areas such as research, enterprise and industry, education and culture, etc. For these instruments the Commission, together with its partners, is directly involved in their design and in developing their investment strategy and endowment. The decision to set up these instruments is taken by the budgetary authorities (i.e. the European Parliament and the Council) on the basis of a Commission proposal.

In shared management, financial instruments can be set up as standalone funds or as sub-funds of a holding fund, later referred to as specific funds (see Figure 1). A holding fund, sometimes also referred to as a 'fund of funds', is a fund set up with the objective of managing different types of instruments. It also allows making contributions from one or more OPs to one or several financial instruments. 
Financial instruments are generally managed by privateor public-sector banks or other financial intermediaries rather than public administrations. For ERDF and ESF instruments, the selection of a fund manager has to comply with EU and national public procurement rules if the management of the fund is tendered out. In situations where public procurement rules do not apply (i.e. in case the fund management contract is not a public service contract), the managing authority can designate the fund manager subject to complying with the relevant State aid rules (see paragraphs 10 to 12).

The EIB group (which comprises the European Investment Fund (EIF) and the European Investment Bank (EIB)) benefits from a special status since they can be appointed as fund managers without a public procurement procedure11. They also manage most of the centrally managed instruments for which the fund manager is designated in the legislative proposal.[2, 43]

EU funds under shared management are considered part of the national or regional budgets and as such are potentially subject to State aid control. When implementing the financial instrument, managing authorities must therefore ensure compliance with State aid rules12. The relevant State aid rules are contained in the new general block exemption regulation (GBER)13 and the Commission's new guidelines for risk finance14, which both came into effect in July 2014.

For each ERDF and ESF financial instrument, the managing authority has to provide evidence that it is either15: conforming with normal market practice (which in practice means that the management of the fund has been selected following an open, transparent and non-discriminatory process); or covered by the de minimis regulation16; or an exempted aid, because it falls under the GBER or falls under a notified aid scheme in accordance with the Commission's guidelines for risk finance.

Centrally managed financial instruments (which do not use national or regional resources, and thus are not part of Member State budgets) fall outside of the scope of the EU's State aid rules, because the main condition of Article 107 TFEU '[...] granted by a Member State or through state resources' is not fulfilled.

During the 2007-2013 programme period financial instruments were used by 25 out of 28 EU Member States. Only Croatia, Ireland and Luxembourg did not use this funding mechanism17. Annex III and IV give an overview of the ERDF and ESF instruments per Member State.

In addition, there were 14 instruments funded through the EAFRD and 6 instruments funded by the EFF. For the 2007-2013 programme period, these two funds did not require Member States to report on financial instruments, so there are no official data in this respect19. However, based on data compiled by the Court, at the end of 2013 the capital endowment of funds co-financed by the EAFRD can be estimated at around 700 million euro, and around 72 million euro for the EFF (in both cases including the national contributions to the programmes).

For the centrally managed instruments, the EU's overall contribution allocated to 2007-2013 instruments in all budgetary areas was about 5.5 billion euro20, spread over 21 financial instruments 21 . These instruments operate across all EU Member States.

Within the EU budget, the European Structural and Investment Funds (ESIFs) are the main source of funding for capital investment and infrastructure, with a total budget of around 450 billion euro for the 2014-2020 programme period.

Since 2011 the European Parliament and European Council has encouraged an increased use of financial instruments22. This political commitment is also reflected in the common provisions regulation (CPR) which provides for an extended use of financial instruments to deliver all five ESIFs (i.e. also the Cohesion Fund) and all thematic objectives for the programmes.

At the end of 2015 the Commission estimated that, for the 2014-2020 programme period as a whole, approximately 21 billion euro will be allocated to financial instruments from the five ESIFs24. Since the average EU contribution to the total endowments of such instruments for the 2007-2013 programme period was around $68 \%$ by the end of 201425 , we estimate that the 21 billion euro amount coming from the EU budget will probably correspond to approximately 31 billion euro in total allocations (not taking account of additional national and private financing that may be provided to the funds outside the ESIF programmes).

Through this audit, the Court examined whether financial instruments were an efficient mechanism to implement the EU budget during the 2007-2013 programme period. In that context our report addresses the following main audit questions: were financial instruments appropriately sized in view of market needs? did financial instruments succeed in attracting private capital? were financial instruments providing revolving financial support? did financial instruments prove to be a cost-efficient method to implement the EU budget? For each of these questions, we examined which lessons could be learnt from the main shortcomings identified. We also assessed to what extent they had been addressed in the regulations applicable to the 2014-2020 programme period.

Our audit covers the period from 2009 to 2015 . We focused on the areas of regional, social, transport and energy policy. In particular, our review covers all ERDF and ESF financial instruments, as well as six centrally managed financial instruments in the areas of social, transport and energy policy. Several issues identified in this report may, however, also affect other areas of the EU budget where such instruments are used.

The audit work consisted of the following elements: a review of various Commission, EIB, EIF and third-party analyses and publications. the analysis of the most recent annual monitoring report published by the Commission in Septem- 
ber 2015, covering all 1025 ERDF and ESF financial instruments. This analysis, based on data reported by the Commission in November 2015, was also made for six26 of the 21 instruments under central management (accounting for an EU contribution of 789 million euro, or $14 \%$ of the total amount of all 21 instruments)27. an examination of 10 case studies of financial instruments implemented in the area of the EU budget covered by this report28, including a field visit to one Member State (Slovakia). [4, 13-17]

A follow-up review of 45 financial instruments audited in compliance audits carried out by the Court since 2009 (whose results were previously reported in our annual reports) and 54 financial instruments examined by our performance audits since 2012. A survey of 85 managing authorities and fund managers involved in the implementation of financial instruments. Out of the 85 entities surveyed, 82 relate to ERDF and ESF instruments under shared management and three to centralised management. There were 66 replies for shared management instruments and two for centrally managed ones. The interviews with more than 40 officials from the Commission, the EIB and the EIF and more than 10 experts from organisations with expertise in the field.

The Court has already carried out numerous examinations of the use of financial instruments, and has reported since 2011 on the findings in several annual reports30 and special reports31. Moreover, the Commission itself, but also the EIB, the EIF, the European Parliament, national audit bodies and private-sector fund managers, have identified a number of issues in recent years which collectively limited the effectiveness of financial instruments during the 2007-2013 programme period. This report builds also on these assessments. [1, 3]

Were financial instruments appropriately sized in view of market needs? 27 Financial instruments are not projects themselves but a delivery tool for funding from the EU budget. In cohesion policy, the decision of a managing authority to deliver OP support through a financial instrument is not so much a decision of whether to invest OP resources or not (this is already predefined in the OP) but rather how to invest: through a oneoff grant or support through a financial instrument providing a repayable financial support. 28 We have therefore examined to what extent the 1025 ERDF and ESF instruments used their capital endowment to provide different forms of financial support to final recipients and analysed several factors contributing to the instruments' low disbursement rates to final recipients during the 2007-2013 programme period: the level of the initial capital endowments of the instruments, whether market needs were properly addressed by the managing authorities and specific difficulties faced by regional financial instruments. We also analysed how similar aspects were dealt with in the case of centrally managed instruments. Excessive capital endowment led to low disbursement rates, avoidance of de-commitment and potential reimbursement at closure
29 The financial instruments disbursement rates have already been examined in several of the Court's annual and special reports32. In this report we analyse the latest available information reported by the Member States to the Commission as at 31 December 2014, published in September 2015. Our analysis of these most recent data shows that a significant number of them continue to face difficulties in using their capital endowments as planned. 30 Table 4 shows the disbursement rates for each of the 25 Member States which implemented financial instruments during the 2007-2013 programme period33. The percentages presented are averages for all ERDF and ESF instruments in the Member State concerned. A significant number of financial instruments were established only in 2012 or afterwards.

By the end of 2014, with only 1 year before the end of the initial eligibility period (31 December 2015), only $57 \%$ of ERDF and ESF instruments' endowments had been disbursed to final recipients. Disbursements were low in particular for financial instruments in Slovakia (21\%), Spain (27\%) and Italy (32\%). Moreover, a further three Member States (Greece, Netherlands, Austria) had disbursed less than half of their initial endowments. 32 Overall, 177 of the 972 ERDF financial instruments (18\%) and 16 of the 53 ESF financial instruments (30\%) had disbursed less than a third of their endowment by the end of 2014. For these 177 instruments, their total unused endowment amounted to 4.2 billion euro as at 31 December 2014. For these instruments, we consider it to be unlikely that the available funding will be used once, even though the Commission has extended the eligibility period until March 2017 (see paragraph 43). The final disbursement rate of the financial instruments can, however, only be assessed at the end of their life cycle, especially as regards those set up towards the end of the programme period.

Did financial instruments succeed in attracting private capital? 62 One of the key advantages of financial instruments is the fact that additional funds can be leveraged, i.e. additional private and public funds can contribute to the funds' capital endowment. The leverage effect measures the extent to which public financing mobilises additional funds. It should inform about the ability of an instrument to attract additional funding, depending on its type, location and final recipients, but also on the choices made by the Commission, the managing authority and/or the fund manager when setting up the instrument. For comparable instruments, a higher leverage would then indicate a better-performing instrument in terms of attracting additional funding. 63 We therefore reviewed the way in which the Commission defines and monitors this leverage effect for both shared and centrally managed instruments and assessed whether the instruments were successful in attracting additional private capital. We also analysed the use made of preferential and risk-sharing arrangements with private partners and of tax agreements in this regard. Commission's measure of leverage for financial instruments 
does not properly take into account the extent to which public financing mobilises additional funds Need for more differentiated leverage ratios to obtain meaningful measurements
Difficulties in identifying leverage of additional private and public capital for shared management instruments.

\section{REFERENCES:}

1. Source: European Commission and EIB, FI Compass - Financial instrument products: Loans, guarantees, equity and quasi-equity, p. 3.

2. Asselberghs R (DG REGIO) (2011) Combination of repayable financial instruments with Grants, presentation to JEREMIE Networking Platform, Brussels 20 May 2011, European Commission. p.43

3. Cowling M (2010) Economic Evaluation of the Small Firms Loan Guarantee (SFLG) Scheme, Report to BIS, Department for Business, Innovation and Skills. p.12

4. Reid A., Nightingale P. (Eds.) (2011) The Role of Different Funding Models in Stimulating the Creation of Innovative New Companies. What is the most appropriate model for Europe? A report to the European Research Area Board. Study funded by the European Commission, DirectorateGeneral Research.p. 13-17 


\section{FINANCIAL INSTRUMENTS AND THE EU STATE AID RULES}

\section{NATELA VASHAKIDZE}

https://doi.org/10.35945/gb.2017.03.014

Asociated Professor of Akaki Tsereteli state University, Kutaisi, Gerogia

\section{DEZDEMONA MAGLAKELIDZE}

Asociated Professor of Akaki Tsereteli state University, Kutaisi, Gerogia

KEYWORDS: FINANCIAL INSTRUMENTS, STATE AID RULES

\section{SUMMARY}

Financial instruments are a delivery tool to provide financial support from the EU budget. Financial support provided to final recipients through financial instruments may take the form of loans, guarantees and equity investments.

If properly implemented, financial instruments provide two specific benefits compared to grants: - the possibility of leveraging the public funds (i.e. mobilising additional private and public funds to complement the initial public funding); and - the revolving nature of their capital endowment (i.e. the use of the same funds in several cycles). The fact that loans have to be paid back and guarantees have to be released or, in the case of equity investments, returned should also have an impact on the behaviour of final recipients, leading to the better use of public funds and reducing the likelihood that the final recipients will become dependent on public support.

We analysed the use made of preferential and risk-sharing arrangements with private partners and of tax agreements in this regard. Commission's measure of leverage for financial instruments does not properly take into account the extent to which public financing mobilises additional funds need for more differentiated leverage ratios to obtain meaningful measurements Difficulties in identifying leverage of additional private and public capital for shared management instruments. 